Forthcoming in Journal of International Economics

\title{
BETTING AGAINST THE STATE: Socially Costly Financial Engineering
}

\author{
Guillermo A. Calvo* \\ University of Maryland, College Park
}

May 29, 1999

\begin{abstract}
The central question raised in the paper is the desirability of state-contingent contracts under imperfect policy credibility. The paper shows a benchmark case in which imperfect credibility of a trade liberalization program is distorting, and the distortion is magnified by statecontingent markets. In addition, it examines the welfare implications of gaining credibility concluding that, in general, more credibility is better than less, and examines the moral hazard faced by policymakers in carrying out reform in case the private sector is able to obtain insurance against its discontinuation.
\end{abstract}

JEL: F 10, 34, 36

\footnotetext{
" This paper was previously circulated under the title "Credibility Crises and State-Contingent Markets: Emerging Markets and Financial Engineering." I am very grateful to David Bowman for his detailed and insightful comments. I have also benefitted from comments by Roger Betancourt, Enrique Mendoza, Esteban Vesperoni, and two anonymous referees. I am solely responsible for remaining errors.

** Corresponding Author: Guillermo A. Calvo, Department of Economics, University of Maryland, College Park, MD 20472-7211, tel. (301) 405-3553, FAX (301) 405-7835, E-mail: calvo@ econ.umd.edu/, http://www.bsos.umd.edu/econ/ciecalvo.htm/.
} 


\section{Introduction}

The recent financial turmoil in emerging markets after the debacle of Mexico's stabilization/reform program in December 1994 has raised many challenging questions. One of

these questions is whether emerging markets would benefit from a wider use of "derivatives" and access to state-contingent contracts. ${ }^{1}$

The present paper discusses a simple analytical framework in which the key uncertainty facing the private sector is whether or not policymakers will be able or willing to carry out economic reform. This is a major challenge for reformers. Aside from the inherent difficulties of charting new waters, reformers also face a private sector that is aware of these difficulties and, thus, is sensitive to the possibility that reforms may fail. To illustrate these issues, the paper considers two types of reforms: (1) output-enhancing reform and (2) trade liberalization. The former can be thought as being associated with institutional changes that help to garner the economy's productive potential (e.g., deregulation, anti-trust legislation, privatization, etc). On the other hand, under trade liberalization, the paper studies a situation in which the government announces a permanent reduction in import tariffs. A key assumption, however, will be that reforms are not fully credible, because the public attaches a positive probability that they will be abandoned. There is, therefore, room for state-contingent contracts, or, more specifically, contracts contingent on the maintenance of reform. ${ }^{2}$ To sharpen the focus, the paper will abstract from any other source of uncertainty.

The model assumes that domestic residents are identical and, hence, the only risk-sharing opportunities involve foreign investors. The latter are risk neutral, while domestic residents are risk averse. Although the benchmark case is one in which both domestic residents and foreign 
investors exhibit the same beliefs about the implementation of reform, the paper also analyzes the implications of a discrepancy between the beliefs of these two types of agents.

The paper shows that, in all relevant cases, greater credibility of reform programs leads to higher social welfare-thus, confirming the view that enhancing the credibility of reform should be one of government's first priorities. The paper's main objective, however, is to examine the role of state-contingent markets, which is the realm of modern financial engineering. In this respect, the central result is that implications are radically different depending on the type of reform. The paper shows that if the government utilizes domestic resident's probabilities to evaluate social expected utility, then there is no room for welfare-improving intervention in the context of output-enhancing reform. However, the paper also shows that, if trade liberalization is not fully credible, even the absence of state-contingent markets welfare-dominates complete markets in a wide set of relevant situations-thus providing a rationale for government intervention. Moreover, if the government is "paternalistic" and utilizes its own probabilities of reform's failure in evaluating social expected utility, there is room for welfare-improving intervention even in the output-enhancing reform case.

The paper offers some comments on endogenous reform when reform is socially costly. It is shown that complete markets in the output-enhancing reform case (with domestic residents and foreign investors sharing the same view about the chances of reform's failure) may remove all incentives for reform to be carried out, because in that case domestic residents would be fully insured against policy changes. This is a dramatic example in which complete markets may interfere with the will and determination of policymakers to carry out reform to full fruition.

The paper is organized as follows: Section II discusses output-enhancing reform, while 
Section III examines trade liberalization; Section IV studies endogenous reform and moral hazard; the paper is closed with conclusions in Section V.

\section{Output-Enhancing Reform}

The main points of this note can be made in terms of a two-period model with no capital accumulation. Consumption and output 'today' are indicated by $c$ and $y^{L}$, respectively, while consumption and output 'tomorrow' in state of nature $s$ are denoted by $x^{s}$ and $y^{s}$, respectively. For the sake of simplicity, we assume two states of nature: $L$ (for "Low") and $H$ (for "High"), such that $y^{H}>y^{L}$. Thus, this situation can be interpreted as one in which 'today' the government undertakes an economic reform program which, if successful and carried out into 'tomorrow,' results in higher output than 'today' (since $\left.y^{H}>y^{L}\right)$. The utility function satisfies the von Neumann-Morgenstern axioms, is intertemporally separable, strictly concave, and exhibits a zero discount rate. Thus, if domestic residents' subjective probability of the reform program's failure (i.e., the probability of state of nature $L$ ) is denoted by $p$, the country's welfare, $W$, could be represented as follows: ${ }^{3}$

$$
W=u(c)+p u\left(x^{L}\right)+(1-p) u\left(x^{H}\right) .
$$

The country is a price/interest-rate taker in international markets, international investors exhibit risk neutrality, and the riskless international rate of interest is zero. Therefore, assuming complete markets, the country faces the following budget constraint:

$$
c+\pi x^{L}+(1-\pi) x^{H}=y^{L}+\pi y^{L}+(1-\pi) y^{H},
$$

where $\pi$ is the probability of the $L$ state of nature according to foreign investors. 
Parameters $p$ and $\pi$ are the probabilities that domestic residents and foreign investors, respectively, attach to the reform program's failure. Thus, they can be interpreted as the degrees of "pessimism" or "lack of credibility" about the program's success by domestic residents and foreign investors. A natural benchmark case is the one in which both sides share the same view and, thus, $p=\pi$. Of the asymmetric cases, perhaps the most relevant is $p<\pi$, i.e., domestic residents are less pessimistic than foreign investors. This would correspond to a situation in which, for example, after several attempts and consequent declining economic welfare, the populace becomes convinced that radical reform is necessary and give full political support for it to be carried out. However, if foreign investors focus more on portfolio diversification than on closely following the country's news, they are likely to stick longer to the outdated view that reform is unlikely to take place. ${ }^{4}$

Maximization of welfare (1) subject to budget constraint (2) yields the following firstorder conditions:

$$
\begin{gathered}
u^{\prime}(c)=\lambda, \\
u^{\prime}\left(x^{L}\right)=\lambda \frac{\pi}{p},
\end{gathered}
$$

and

$$
u^{\prime}\left(x^{H}\right)=\lambda \frac{1-\pi}{1-p}
$$

where $\lambda>0$ is the associated Lagrange multiplier. 
The following Proposition is an immediate consequence of the above first-order

conditions:

Proposition 1. If $p=\pi$, then $c=x^{s}, s=L, H$. Furthermore,

$$
\pi>p \Rightarrow x^{L}<c<x^{H}
$$

and

$$
\pi<p \Rightarrow x^{L}>c>x^{H}
$$

The following Proposition refers to changes in social welfare as a result of changes in the degrees of pessimism:

\section{Proposition 2.}

$$
\pi \geq p \Leftrightarrow \frac{d W}{d p} \leq 0
$$

Furthermore, there exists some number $\pi^{c}>p$ (which may be a function of $p$ ), such that

$$
\pi<\pi^{c} \Rightarrow \frac{d W}{d \pi}<0
$$

Finally,

$$
\left.\frac{d W}{d \pi}\right|_{\pi \equiv p}<0 . \square
$$

Proof of Proposition 2. Follows trivially from the Lagrangean expression corresponding to the maximization of utility (1) subject to budget constraint (2), and the Envelope Theorem.

In words, and in inverse order, by (10), in the benchmark case in which domestic 
residents and foreign investors share the same view, an increase in the degree of pessimism lowers social welfare. By (9), the same holds in a wide spectrum of cases in which foreign investors are not "too pessimistic," i.e., $\pi \geq \pi^{c}$. Finally, by (8), assuming that initially domestic residents are more optimistic than foreign investors-the relevant asymmetric case in which $\pi>p$-then social welfare declines if domestic residents become more pessimistic. However, the implication is reversed if initially domestic residents are more pessimistic than foreign investors. ${ }^{5}$ The overall conclusion is that in the relevant cases an increase in the degree of pessimism or lack of credibility is likely to be detrimental to social welfare.

Consider now the case in which individuals are 'unduly' pessimistic. More precisely, let us assume that the government knows that the probability of failure is $p^{G}$ but domestic residents and foreign investors are more pessimistic. The question arises: is there room for welfareenhancing government intervention? There is no obvious answer to this question. For, the answer requires first deciding what is the relevant welfare concept under the present circumstances. If this is a one-shot game, then the relevant welfare concept would seem to be (1), where probability $p$ is the public's subjective probability of reform's failure which, by assumption, is larger than $p^{G}$. Under this criterion the private sector maximizes social welfare and there is no room for government intervention. This does not mean that the government has no role, though, since one of its key roles would still be to gain credibility and improve its communication skills.

On the other hand, consider an artificial set up in which exactly the same reform experiment is carried out in a large number of mutually stochastically independent locations. Then, by the law of large numbers, ex post individuals would be able to have an accurate 
estimate of the probability of reform failure. Thus, if $p^{G}$ was right, then, looking back, individuals would wish the government did something to correct their mistake, even though intervention would not have maximized their expected utility at the time they made their consumption decisions. Thus, it could be argued that on the basis of ex post utility, the relevant probability in evaluating social welfare is $p^{G}$, not $p$. I conjecture that this artificial example could be adapted to an infinite-horizon set up with learning. Assuming that the government is right, then individuals will learn over time that the true probability of reform failure is $p^{G}$. Thus, again, looking back, individuals would wish the government did something to correct their mistake.

Notice that the same welfare concept would be utilized by a "paternalistic" government that maximizes its own expected utility (and, therefore, utilizes $p^{G}$ instead of $p$ ).

In the benchmark case in which $p=\pi>p^{G}$, for example, by Proposition 1, 'tomorrow' consumption in the low output state would be too large with respect to 'tomorrow' consumption if the state is high output. Optimal policy under these conditions is summarized in the following Proposition:

Proposition 3. Let $p=\pi>p^{G}$, and the social welfare be given by

$$
W=u(c)+p^{G} u\left(x^{L}\right)+\left(1-p^{G}\right) u\left(x^{H}\right) .
$$

Then, the social optimum is achieved setting a state-contingent consumption $\operatorname{tax} \tau^{s}>-1, s=L, H$, such that

$$
1+\tau^{L}=\frac{p}{p^{G}}>1,1+\tau^{H}=\frac{1-p}{1-p^{G}}<1,
$$


and taxes are rebated to the public in a lump-sum manner, i.e., at equilibrium, lump-sump subsidies $=\tau^{s} x^{s}$, if state of nature $s=L, H$, takes place.

Proof of Proposition 3. The planner maximizes (11) subject to budget constraint (2) (where $\pi=$ p). Therefore, the first-order conditions for this problem are

$$
\text { (a) } u^{\prime}(c)=\lambda^{G},(b) u^{\prime}\left(x^{L}\right)=\frac{p}{p^{G}} \lambda^{G} \text {, and }(c) u^{\prime}\left(x^{H}\right)=\frac{1-p}{1-p^{G}} \lambda^{G}
$$

where $\lambda^{G}$ is the Lagrange multiplier associated with the planner's optimization problem.

Under these circumstances, for the domestic resident the after-tax price for $c$ is 1 , for $x^{L}$ is $\left(1+\tau^{L}\right) p$, and for $x^{H}$ is $\left(1+\tau^{H}\right)(1-p)$. Thus, given (12), the individual will set

$$
\frac{u^{\prime}\left(x^{L}\right)}{u^{\prime}(c)}=\frac{p}{p^{G}}, \text { and } \frac{u^{\prime}\left(x^{H}\right)}{u^{\prime}(c)}=\frac{1-p}{1-p^{G}}
$$

which equals the ratio obtained dividing (13 b) by (13 a), and (13c) by (13a), respectively. From this result and the tax rebate assumption the proof of Proposition 3 immediately follows.

Remark 1. An implication of Proposition 3 is that the optimum is achieved by taxing consumption when output is low-a politically unpalatable policy since the private sector would be hit by low output and higher taxes-and subsidizing it, otherwise.

To summarize, when reform is output-enhancing, imperfect credibility is no ground for government intervention, unless ex post expected utility is the relevant welfare concept, or the government is paternalistic. 


\section{Trade Liberalization}

Results are radically different if lack of credibility generates distortion as in Calvo (1986), Calvo and Drazen (1998) and Mendoza and Uribe (1996). Consider, for example, the case in which the government lowers import tariffs to zero 'today' and promises to keep them low 'tomorrow.' However, domestic residents and international investors believe that there is a probability $p$ that the trade liberalization program will not be carried out into 'tomorrow' and, instead, tariffs will be raised to $\theta>0 .^{6}$ To focus on the distortionary effect of lack of full credibility and abstract from fiscal considerations, we assume that the tariff is fully rebated to domestic residents in the form of lump-sum subsidies.

Output is constant at level $y$, domestic residents have no use for domestic output and, thus, consumption entirely consists of imported goods. Using the same notation as in previous section, and identifying $L$ with policy reversal, equilibrium lump-sum subsidies if state $L$ occurs equal $\theta x^{L} \equiv g$, where $x^{L}$ is the market-determined consumption if, contrary to the policymaker's promise, the tariff is imposed. Hence, under complete contingent markets and, again, assuming that the international riskless interest rate is zero, the budget constraint for domestic residents is given by the following expression:

$$
2 y+p g-c-p(1+\theta) x^{L}-(1-p) x^{H}=0
$$

Consequently, domestic residents maximize utility (1) subject constraint (15), which yields the following first-order conditions:

$$
u^{\prime}(c)=\lambda
$$


and

$$
\begin{gathered}
u^{\prime}\left(x^{L}\right)=\lambda(1+\theta), \\
u^{\prime}\left(x^{H}\right)=\lambda .
\end{gathered}
$$

Proposition 4. Let us assume state-contingent markets. Then (1) $y<c=x^{H}>x^{L}$, and (2) $c$ and $x^{s}$, $s=L, H$, are increasing functions of the degree of pessimism about the continuation of the trade liberalization policy $p$.

Proof of Proposition 4. The statement about the consumption pattern, $c=x^{H}>x^{L}$, follows trivially from first-order conditions (16), (27) and (18). The economy as a whole faces the following budget constraint:

$$
2 y-c-p x^{L}-(1-p) x^{H}=0
$$

which, given the consumption pattern, requires $c>y$.

We will now turn to prove statement (3) in Proposition 4. Since $c=x^{H}$, we can write equation (19) as

$$
2 y-c(2-p)-p x^{L}=0
$$

Moreover, by first order conditions (16) and (17),

$$
\frac{u^{\prime}\left(x^{L}\right)}{u^{\prime}(c)}=1+\theta
$$


Figure 1 depicts equations (20) and (21). The downward-sloping straight line corresponds to budget constraint (20), while the heavy upward curve depicts first-order condition (21). Initial equilibrium is at point $\mathrm{A}$. The dashed curve is budget constraint (20) after $p$ rises by $\Delta p$. The budget constraint pivots on the point $c=x^{L}=y$. Thus, as a result of $\Delta p>0$, equilibrium shifts from point A to point B, proving point (3) in Proposition 4.

Next we will discuss the effect of lack of credibility on social welfare (again assuming that domestic residents and foreign investors share the same view, i.e., $p=\pi$ ).

Proposition 5. Let us assume the existence of complete contingent markets. Then, for a neighborhood of full credibility, i.e., $p=0$, an increase in the degree of pessimism about the continuation of trade liberalization, $p$, lowers social welfare.

Proof of Proposition 5. Consider the Lagrange expression associated with the maximization of expected utility (1) subject to budget constraint (15). Thus, totally differentiating the Lagrange expression, taking into account first-order conditions (16)-(18), it follows that

$$
\frac{d W}{d p}=u\left(x^{L}\right)-u\left(x^{H}\right)+u^{\prime}\left(x^{H}\right)\left(x^{H}-x^{L}\right)+u^{\prime}\left(x^{H}\right) p \theta \frac{d x^{L}}{d p} .
$$

Thus, by strict concavity of function $u$, we have that the expression in (22) is negative if $p=0$ (recalling that $x^{L}<x^{H}$ ). Proposition 5 now follows from continuity.

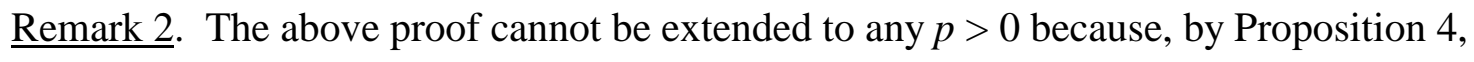
$\frac{d x^{L}}{d p}>0$. However, numerical analysis in terms of iso-elastic utility functions suggests that the inverse relationship between the degree of pessimism, $p$, and social welfare is very general. For a plausible range of elasticity parameters, the inverse relationship holds for values of $\theta$ exceeding 
50 (i.e., tariffs of 5000 percent!). Thus, again in this case, enhancing government's credibility is likely to be socially desirable.

Calvo (1986) shows that lack of credibility is tantamount to an intertemporal distortion, from which it readily follows that government intervention-in the form, for instance, of controls on capital mobility-is socially desirable, even though the welfare criterion is based on private sector's beliefs (recall the discussion in the previous section). Now we will tackle a subtler question, a key motivation for the present paper, namely, Is it optimal to limit state-contingent markets when trade liberalization is not fully credible? More specifically, we will study the net social benefit of disallowing contingent markets.

In the absence of state-contingent markets, 'tomorrow' consumption $x$ is given by

$$
x=\frac{2 y-c+g}{1+\theta}, g=\theta x \text {, if trade liberalization is abandoned },
$$

or,

$$
x=2 y-c \text {, if trade liberalization is continued. }
$$

By (1), (23) and (24), expected utility maximization by domestic residents is equivalent to maximizing the following expression with respect to $c$ (taking (23) and (24) into account):

$$
u(c)+p u\left(\frac{2 y-c+g}{1+\theta}\right)+(1-p) u(2 y-c) .
$$

Hence, in the absence of state-contingent markets, domestic residents' utility maximization yields the following first-order condition (noting that by (23) and (24) the equilibrium value of $x$ 
is the same independently of the state of nature):

$$
u^{\prime}(c)=u^{\prime}(x)\left(\frac{p}{1+\theta}+1-p\right)
$$

We are now ready to prove a central result of this section.

Proposition 6. Let utility index $u$ equal the natural logarithm function. Hence, for $0<p<1$, and with no government intervention, social welfare is higher under no state-contingent markets than under complete state-contingent markets. If $p=0$ or $p=1$ then social welfare is the same under the two market structures.

Proof of Proposition 6. See Appendix.

Lastly, one can compute the income-equivalent welfare gains or losses from different policies. In the present quasi-static framework it is likely that these welfare gain/losses be small (normally less than 1 percent). This is actually confirmed by numerical analysis in the family of iso-elastic utility functions. ${ }^{7}$ However, the welfare costs of contingent relative to non contingent markets are significant. For example, in the logarithmic case, if $\theta=25$ percent and $p=20$ percent, the above ratio is roughly 10.

\section{Moral Hazard}

The above discussion assumed that capital market contracts are fully honored and reform probabilities are independent of those contracts. One obvious extension is to allow for debt repudiation, but the latter will not be analyzed here because the present framework has little to add to previous findings. Of greater interest is the possibility that the probability of reform be endogenous and reflects the type of capital market contracts implemented at equilibrium. 
To illustrate, consider the model in Section II in which reform implies high output 'tomorrow,' while no reform implies maintaining present low output level. By Proposition 1, in the benchmark case in which domestic residents and foreign investors share the same view, i.e., $p$ $=\pi$, then at equilibrium consumption will be the same irrespective of whether reform is being carried out. Domestic consumers would be completely insulated from the outcome of the reform process. Thus, if there is just a small social cost associated with reform, policymakers will have no incentive to implement it! Under these circumstances, the only rational expectations equilibrium outcome corresponds to the case of no reform with probability 1, i.e., $p=\pi=1$, giving rise, by (10), to the worst-case scenario. In contrast, if state-contingent markets are not complete, and consumption if reform takes place, $x^{H}$, exceeds consumption if it does not, $x^{L}$, then it becomes more likely that reform will be carried out. Actually, if the marginal social cost of reform is small, policymakers could be induced to reform with probability 1 , i.e., $p=0$, which leads to a first-best scenario. This suggests that a reason for not encouraging the development of complete markets, especially in countries that lag considerably in terms of institutional development, is that otherwise policymakers may loose their drive to push reform to full fruition. ${ }^{8}$

Interestingly, however, the above result does not extend to the trade liberalization example discussed in Section III. By Proposition 3, under complete markets $x^{H}>x^{L}$ which may not interfere with reform if its marginal social cost is small enough. Actually, incentive problems would arise if there were no state contingent markets. By (23) and (24), 'tomorrow' consumption is independent of whether trade liberalization is carried out. Therefore, policymakers may choose to eschew reform, i.e., set $p=0$. In the present economy social welfare 
is the same whether or not trade reform is undertaken. This is so because the model has abstracted from traditional static gains from trade. Thus, complete and incomplete statecontingent markets may lead to the same outcome in terms of social welfare. Introducing static gains from trade implies that even though income in terms of tradables would be the same 'tomorrow', irrespective of trade liberalization, 'tomorrow' utility index will be higher if reform is carried out-thus breaking the tie in favor of reform. Therefore, moral hazard problems associated with complete markets seem to be less serious for trade liberalization programs than for sheer output-enhancing ones.

\section{Conclusions}

Economic reform is a complex process involving a few courageous technicians, supported by visionary politicians, whose success depends among many other things on the existence of appropriate exogenous conditions. Therefore, one of the central difficulties faced by reformists is lack of complete credibility in their ability or willingness to undertake a very strenuous, and occasionally life-threatening, task. It would, therefore, be surprising that unfettered market activity should be socially optimal when policymakers' credibility is at stake. The present paper confirms this view, either because the existence of a full set of markets would magnify distortion, or because it may interfere with the reformists' heroic drive.

Financial markets analysts probably just see the last stage of the game when they recommend that emerging market economies open their doors to state contingent contracts. With complete markets, for example, domestic residents may be compensated for lack of reform and, thus, they may ceteris paribus be better off than if they had bought no insurance. But the ceteris paribus assumption could be very strong. The existence of contingent markets changes the 
nature of equilibrium. Thus, looking at the last stage of the game is simply naive and may be misleading.

Having shown that state-contingent markets could be socially costly does not automatically imply that state-contingent contracts-especially those that are, implicit or explicitly, contingent on reform's success or failure-should be controlled or banned. First, as illustrated in the paper, gaining credibility is, as a general rule, welfare improving. Moreover, credibility is unlikely to be gained by blocking incentive-compatible financial contracts. Second, financial markets are hard to regulate; thus, otherwise redundant and complex financial instruments are brought to life by skillful financial engineers as more familiar instruments are banned or controlled. Unsuccessful regulation also diminishes the policymaker's credibility.

However, the paper raises a warning flag about policies that facilitate financial engineering in reforming economies. An underdeveloped financial sector can help maneuvering transition, lowering the distortion costs of not-fully-credible policies. The effective life of this "window of opportunity" may be short but there is no clear reason why policymakers should not want to take advantage of it.

In closing, it is worth recalling that the framework used in this paper is extremely simple and unrealistic. Its main contribution is to provide a first look at key issues that preoccupy financial analysts and policymakers after the resurgence of capital mobility in emerging markets. The next obvious step would be to bring into the picture realistic financial considerations (including moral-hazard issues associated with the existence of a 'lender of last resort') that, even under free-market conditions, would prevent the existence of a full set of contingent markets. In that context, opening state contingent markets would be a much harder exercise in second-best economics. Hopefully, the present paper will help to shed some light on that intricate world. 


\section{Appendix: Proof of Proposition 6}

By (15)-(18) the (ex ante) expected utility if markets are complete is given by

$$
2 \ln \left(\frac{2 y}{2-p+\frac{p}{1+\theta}}\right)-p \ln (1+\theta)
$$

On the other hand, by (23), (24) and (26), expected utility if there are no state-contingent markets satisfies

$$
2 \ln \left(\frac{2 y}{2-p+\frac{p}{1+\theta}}\right)+\ln \left(\frac{p}{1+\theta}+1-p\right)
$$

Note that expressions (27) and (28) are equal for $p=0$ and $p=1$, which proves the last statement in Proposition 6. Let us now take the difference between (28) and (27):

$$
\ln \left(\frac{p}{1+\theta}+1-p\right)+p \ln (1+\theta) \equiv \varphi(p)
$$

Hence,

$$
\varphi^{\prime \prime}(p)=-\left(\frac{1+\theta}{\theta}-p\right)^{-2}<0 .
$$

Thus, $\varphi(0)=\varphi(1)=0$ and, by (33), $\varphi$ is strictly concave. Consequently,

$$
\varphi(p)>0,0<p<1
$$

which shows that welfare associated with the absence of state-contingent markets exceeds the 
one associated with complete markets if $p \varepsilon(0,1)$, and completes the proof of Proposition 6 .

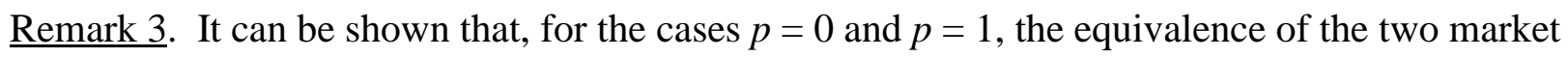
structures holds for any function $u$ allowed by our postulates. This is intuitive because given that domestic residents and foreign investors share the same expectations, each of those cases exhibit no uncertainty and, thus, state-contingent markets are redundant. Thus, if we define $\psi(p)$ as the difference between social welfare under no state-contingent markets and under complete statecontingent markets, $\psi(0)=\psi(1)=0$. Furthermore, it seems natural to conjecture the existence of a "neighborhood" of utility indexes around the natural logarithm function such that for utility indexes in that neighborhood, function $\psi$ exhibits property (31), i.e.,

$$
\psi(p)>0,0<p<1 .
$$

In words, for utility indexes close enough to the natural logarithm function, social welfare under no state-contingent markets is greater than complete state-contingent markets. We can make this notion of "neighborhood" more precise and rigorously prove the conjecture if we confine ourselves to the class of functions $u$ such that

$$
u(z)=\frac{z^{1-\alpha}}{1-\alpha}, \alpha \geq 0
$$

The logarithmic case corresponds to $\alpha=1$. Thus, one can show that there exists a neighborhood around $\alpha=1$ such that if $\alpha$ belongs to that neighborhood, the corresponding function $\psi$ satisfies condition (32). ${ }^{9}$

Numerical simulations further show that to reverse the relationship expressed in Proposition 6 it seems necessary for $\alpha$ to be lower than 0.1 , which is considerably smaller than 
any empirical estimate of parameter $\alpha$. Thus, we can safely conclude that if trade liberalization does not enjoy full credibility, then allowing for state-contingent markets is likely to be detrimental to social welfare. 


\section{References}

Calvo, Guillermo A., 1986, “Temporary Stabilization: Predetermined Exchange Rates,” Journal of Political Economy, December, 1319-1329.

—_, 1988, “Costly Trade Liberalizations: Durable Goods and Capital Mobility,” Staff Papers, IMF, 35, No. 3, September, 461-473.

— , and Allan Drazen, 1998, “Uncertain Duration of Reform: Dynamic Implications,” Macroeconomic Dynamics, 2, 4, December, 443-455.

— Securities Markets," Journal of International Economics, this issue.

Kreps, David M., 1990, A Course in Microeconomic Theory; Princeton, NJ: Princeton University Press.

Mendoza, Enrique G., and Martín Uribe, 1996, “The Syndrome of Exchange-Rate-Based Stabilizations and the Uncertain Duration of Currency Pegs," manuscript, Federal Reserve Board, August. 


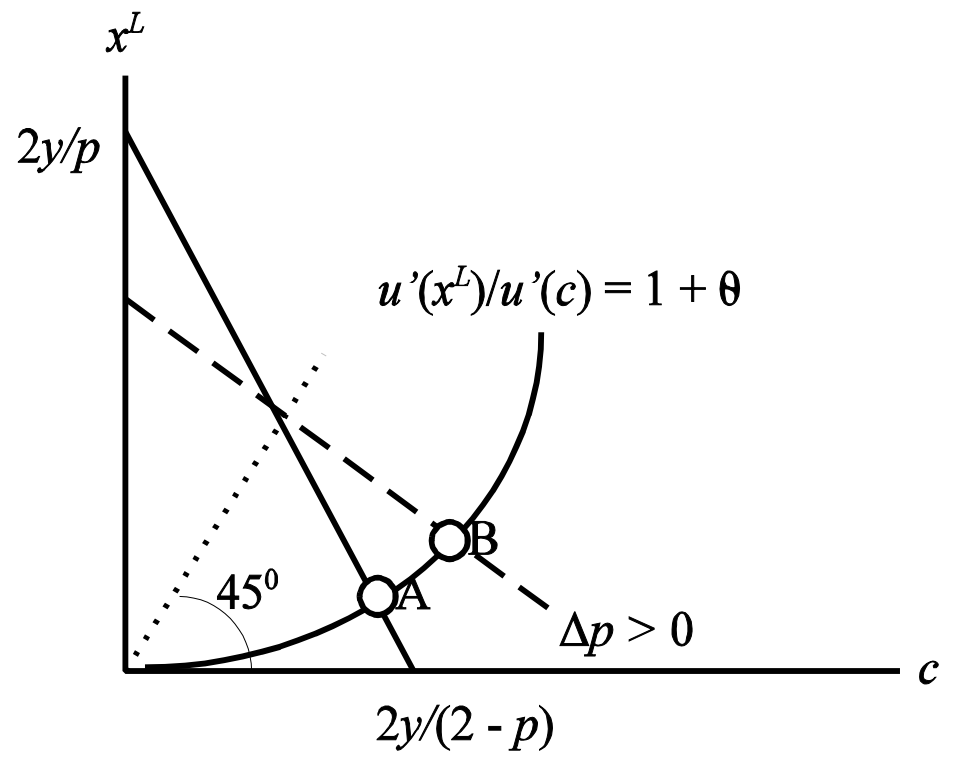

Figure 1. Determination of $c$ and $x^{L}$ 


\section{Notes}

1. A common opinion by financial analysts is that Mexico's crisis would have been cushioned if market participants were allowed to "short" the peso, i.e., borrow in pesos, presumably to hedge. As the argument goes, at the time of crisis there would have been a group of players that were contractually obligated to buy pesos, helping to prop up its value against the dollar and, thus, slow down its steep decline.

2. In reality there seems to be no contract directly linked to the maintenance or discontinuation of reform. However, there are options and future contracts on exchange rates and other variables that are themselves linked to reform. Thus, these contingent contracts are proxies for the contracts examined in this paper.

3. For technical reasons we further assume that function $u$ is twice-continuously differentiable.

4. For a discussion of incentives to learn about a particular country in a globalized capital market, see Calvo and Mendoza (1999).

5. The reason for this is that when $p>\pi$, domestic residents choose $x^{L}>x^{H}$. Recall that $x^{L}$ and $\pi$ are consumption and its price, respectively, if reform is abandoned. Thus, when $\pi$ rises there is a negative income effect.

6. To simplify the exposition, in this section I will assume that both domestic residents and foreign investors share the same view of policy reversal, i.e., $p=\pi$.

7. However, as shown in Calvo (1988), allowing for durable goods could greatly magnify these costs.

8. It is worth noting that the tradeoff between insurance and efficiency under incentivecompatibility constraints is well known in the microeconomic literature. See, for instance, Kreps (1990). 
9. The formal proof utilizes the fact that for $\alpha=1, \psi^{\prime}(0)>0$ and $\psi^{\prime}(1)<0$, and that these derivatives are continuous functions of $\alpha$. 